\section{Palliative care in a Danish general practice}

AM Larsen1, MF Andersen1, MA Neergaard2, T Gorlen1 1 Lægerne Søborg Torv, Denmark (general practice)

${ }^{2}$ Aarhus University Hospital, Denmark

\section{Background}

Most terminally ill patients wish to die at home and this requires specific competences in end-of-life-care amongst general practitioners (GP).

\section{Aim}

To quantify and evaluate the palliative trajectories in a Danish general practice that has systematically followed patients with palliative needs over the last five years.

\section{Hypothesis}

Number of home-deaths (including nursing homes) over a threeyear period was expected to be larger than the national average in a Danish general practice in which one of the GP's has specialized in palliative care.

Table 1 Patient characteristics according to place of death

\begin{tabular}{|c|c|c|c|c|}
\hline Place of death & All & Home & Out & \\
\hline & number (\%) & number (\%) & number (\%) & $p^{\star}$ \\
\hline Total & $201^{\star \star}$ & 99 & 93 & \\
\hline Gender & & & & 0.09 \\
\hline female & $112(56)$ & $62(63)$ & $47(51)$ & \\
\hline male & $89(44)$ & $37(37)$ & $46(49)$ & \\
\hline Age, years & & & & $<0.01$ \\
\hline $47-60$ & $7(3)$ & $1(1)$ & $5(5)$ & \\
\hline $61-70$ & $22(11)$ & $4(4)$ & $15(16)$ & \\
\hline $71-80$ & $44(22)$ & $15(15)$ & $26(28)$ & \\
\hline $81-$ & $128(64)$ & $79(80)$ & $47(51)$ & \\
\hline Cause of death & & & & $<0.01$ \\
\hline cancer & $51(25)$ & $23(23)$ & $25(27)$ & \\
\hline other $r^{\star \star \star}$ & $68(34)$ & $18(18)$ & $49(53)$ & \\
\hline old of age & $48(24)$ & $48(49)$ & $0(0)$ & \\
\hline missing & $34(17)$ & $10(10)$ & $19(20)$ & \\
\hline
\end{tabular}

* pearson's chi-square-test, ${ }^{* *}$ in 9 patients place of death was missing, ${ }^{\star \star \star} \mid$ ung-, heart-disease, dementia and other

Table 2 Place of death. Odds ratio (OR) for death at hospital/hospice (out)

\begin{tabular}{|c|c|c|c|c|c|c|c|c|c|c|}
\hline $\begin{array}{l}\text { Place of death } \\
\text { number }(\%)\end{array}$ & All & Home & Out & $p$ & $\begin{array}{c}\text { Unadjusted } \\
\text { OR }\end{array}$ & $(95 \% \mathrm{Cl})$ & $p$ & $\begin{array}{l}\text { Adjusted } \\
\mathrm{OR}^{\star}\end{array}$ & $(95 \% \mathrm{Cl})$ & $p$ \\
\hline Physician & & & & $<0.01$ & & & & & & \\
\hline $\begin{array}{l}\text { GP palliative } \\
\text { specialist }\end{array}$ & $49(24)$ & $35(35)$ & $12(13)$ & 0.087 & ref. & - & - & ref. & - & - \\
\hline Other GP & $51(25)$ & $44(45)$ & $6(6)$ & - & 0.398 & $(0.14-1.17)$ & 0.093 & 0.301 & $(0.07-1.5)$ & 0.098 \\
\hline Not GP & $101(50)$ & $20(20)$ & 75 (81) & - & 10.937 & $(4.8-24.49)$ & $<0.001$ & 9.773 & $(2.45-38.93)$ & 0.001 \\
\hline
\end{tabular}

* adjusted for age, gender, primary diagnosis and cause of death

\section{Methods}

Adult patients affiliated with a large (6500 patients) Danish 4doctor general practice located in a Copenhagen suburb, who died between January 1st 2015 and July 31st 2018 were identified. Patients who died by accident or suicide were excluded. Information about age, gender, diagnosis, place of death and physician being primarily responsible for the palliative phase was retrieved from the patients files.

\section{Results}

201 patients were included in the study. The mean age at time of death was 82.4 years. Nine-ty-nine patients (49\%) died at home or in a nursing home (called home), 93 patients (46\%) died at a hospital or in a hospice (called out) (Table 1).

As compared to both national, regional and municipal data from the period 2012-2014 the proportion of home-death was higher in the study population (Figure 1).

Age and cause of death were significantly different between patients who died at home away from home (Table 1).

Dividing patients into three groups based on which doctor was responsible in the palliative phase ("GP palliative specialist" (1 doctor), "other GP" (5 different doctors) and "not a GP"), odds ratio (OR) for death at hospital/hospice was found to be lower for the group of other GP's as compared to the GP palliative specialist, also after adjustment for age, gender, diagnosis and cause of death (Table 2). If no GP was involved odds was 9 times higher for death at hospital/hospice.

\section{Conclusion}

Proportion of home-death was higher in the studied Copenhagen suburb general practice as compared to national data.

This difference may depend on a general increased focus on palliative care in this clinic. A GP in the palliative phase greatly improves chances of home-death. 